\title{
Improving the indoor air quality using the individual air supply system
}

\author{
E. Zender-Świercz ${ }^{1}$
}

Received: 17 January 2017/Revised: 15 May 2017 / Accepted: 13 July 2017/Published online: 24 July 2017

(C) The Author(s) 2017. This article is an open access publication

\begin{abstract}
Indoor air quality attracts great interest. Many dwellings are ventilated naturally. The article presents the gravity system conversion into individual air supply system, which can be equipped with air fan. This solution's impact on the interior microclimate was analyzed. The proposed solution uses the lower natural ventilation ducts sections, which are not normally used as air supply channels to bring air to the housing. Exhaust grilles were located in the adjacent rooms. Individual air supply system with switched off fan improves indoor air quality insufficiently; however, switching on the device causes a very significant change. A large carbon dioxide concentration reduction (which was used as an air quality indicator) has been confirmed by rigorous statistical analysis, the results of which were presented in the article.
\end{abstract}

Keywords Building ventilation - Indoor microclimate . Carbon dioxide concentration - Carbon dioxide reduction . Individual air supply system · Improving air quality

\section{Introduction}

Indoor air quality is important to human health and the building structure condition. This confirms the scientific interest; the research results on residential buildings can be

Editorial responsibility: J. Aravind.

E. Zender-Świercz

ezender@tu.kielce.pl

1 Department of Building Physics and Renewable Energy, Faculty of Environmental, Geomatics and Energy Engineering, Kielce University of Technology, Kielce, Poland found in the literature (Nielsen and Drivsholm 2010). The external conditions' impact on the interior microclimate was described by many authors (Chang et al. 2004; Niachau et al. 2008) whose studies did not include a temperate climate and does not take into account the external conditions' impact on the airflow in the natural ventilation ducts or infiltration and exfiltration.

A desire for human health and life is to create the indoor conditions in which people can breathe fresh and pollution-free air. At the same time, it is important to maintain building low energy consumption. The vast majority of residential buildings are ventilated in a natural way, which does not create indoor conditions comfort what was described in Nantka (2008). However, one of the strategies to reduce the energy consumption is exactly the natural ventilation. In the literature (Omrami et al. 2017), the analysis model of the natural ventilation in the holistic process of multi-family building design was proposed. The quick and cheap methods are developed to use on the early stage of building design, and more detailed methods are to use on the more advanced stages. The influence of natural and mechanical ventilation on the dilution of pollutant with taking into account the influence on energy consumption was analyzed in Ben-David and Waring (2017). The results of the conducted by researchers analysis showed that natural ventilation sufficiently dilutes the pollutant in the office premises and the energy consumption is lower. However, the filtration of PM2.5 is not sufficient. The researchers (Nomura and Hiyama 2017) analyzed the influence of shape of building on the efficiency of natural ventilation. They have done the research in tropical and subtropical zone. The conclusion of their analysis is the necessity of taking into account the geometric parameters of building in the ventilation design process. 

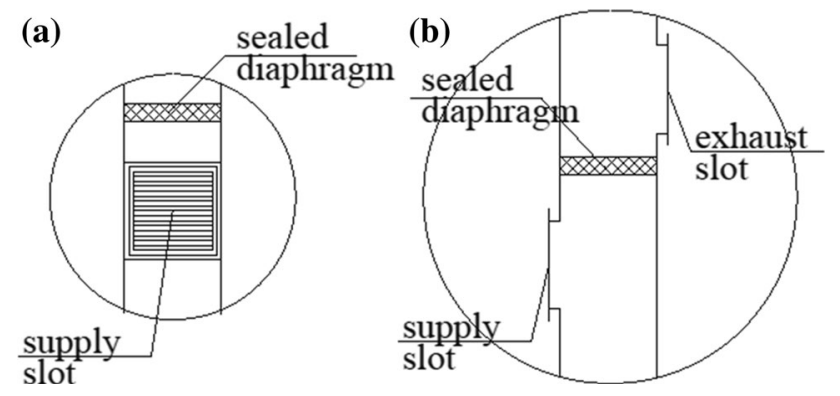

Fig. 1 Schematic supply and exhaust vent grates location in the duct equipped with a sealed solid element separating the supply and exhaust air stream. a Front view. b Cross section through the channel

In this paper, the individual air supply system was proposed to improve the indoor air quality. The solution allows for the lower ducts sections use of natural ventilation, which are not normally used as ventilation elements. This is made possible by placing the sealed solid element separating the supply and exhaust air stream (Fig. 1). The second important condition is placing the supply and exhaust vent grates in different rooms. The external air is flowing from the air intake to the handler unit. Then it is flowing to the twelve vertical ventilation shafts (Fig. 2a). The air is flowing in each vertical shaft to the premises, where the ventilation grates are located. There is the sealed solid element separating the supply and exhaust air stream above the inflow grate, in each ventilation shaft. The outflow grate is located above this sealed element. The location of the ventilation grates and the sealed solid element in the one of the vertical ventilation shafts is presented in Fig. 2b.

The article presents improvements in the interior microclimate with the proposed solution. It presents two options: when the air flows through the individual air supply system naturally or when a ventilator moves air through the duct. The analysis covered flats in multi-family four-story buildings located in the city in the temperate climate in the third climatic zone. The study was conducted over the years 2010-2015. For the analysis data from the winter months, i.e., December, January and February were selected. A concentration of carbon dioxide $\left(\mathrm{CO}_{2}\right)$ is used as the measure of air quality. This parameter was chosen because people are the main source of pollution. The man exhales the carbon dioxide in the respiratory process. In this way, he raises the gas concentration in the internal air. The technological processes are not carried out in the residential premises. Therefore, there are no extra pollutants which should be removed. This means that carbon dioxide concentration can be a reliable indicator of indoor air quality. Furthermore, it is possible to detect even at low concentrations. In the literature (Piotrowski and Zender-
Świercz 2008; Piotrowski et al. 2008, 2010, ZenderŚwiercz and Piotrowski 2008, 2009, 2010, 2011), indoor air quality preliminary research results are presented. The measured values of the analyzed parameter are in reference to the specified limit values as $700 \mathrm{ppm}$ above $\mathrm{CO}_{2}$ concentration in the outside air by ANSI/ASHRAE (2016) and 1000 ppm by McQuiston et al. (2005).

\section{Materials and methods}

\section{Subject of the study}

The analyzed apartments were located in multi-family buildings. The objects were insulated and equipped with the sealed windows and doors. During the construction phase, the lower ducts sections use of natural ventilation was planned as the part of air supply. The air drawn from the outside through the wall air intake located $2 \mathrm{~m}$ above the surface of the ground flows and led by the ducts placed in the underground garage to the central air handler equipped with the filters set and air heater. The air is flowing in ducts from central air handler to the lower sections of natural ventilation ducts. The location in underground garage lets heat the air inside the ducts by the surrounding air. It is to save energy for heating of the supply air. In the house buildings, the air supply was in the hallway and exhaust in the kitchen (the upper section of the same duct) and the bathroom (a separate duct). The air supply is also brought by the leaks in the housing building. The amount of air flowing in this way is influenced by the wind (its direction and speed) that issue is differently undertaken in the literature by the authors (Piotrowski et al. 2015; Zender-Świercz and Piotrowski 2011). However, due to the building high tightness the study focuses on the air inflow through individual air supply systems.

In each apartment, the measurement was carried out in the hallway and in the bedroom. The air inflow was realized in the hallway. The air was flowing to the bedroom through the doors between the premises. This flow is a result of the overpressure. In spite of the localization of the outflow grates in the kitchen and in the bathroom, the air was flowing into the rooms and was flowing out by the exfiltration and by the diffusion in the building casing. The improvement in the air quality in these rooms confirmed this flow. The measurements were performed during the night as conditions throughout the whole building.

\section{The way of measuring}

The measurements were carried out, and for this purpose, the indoor air quality monitors were used (Fig. 3). These 
(a)

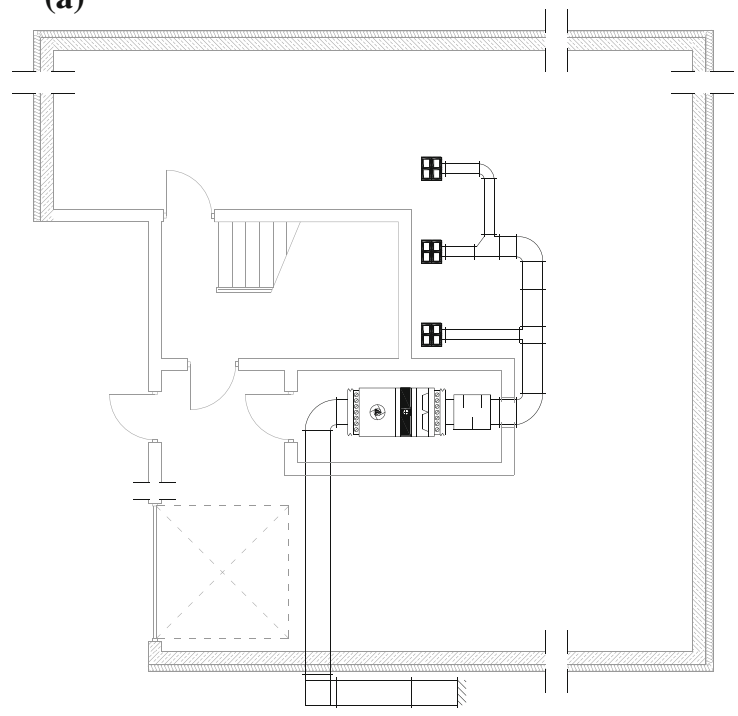

(b)

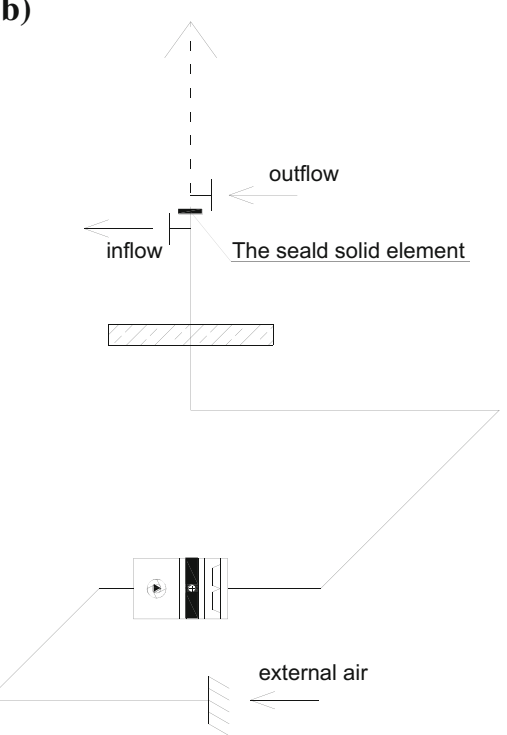

Fig. 2 Schema of ducts layout. a View from above. b Axonometric view of one vertical ventilation shaft

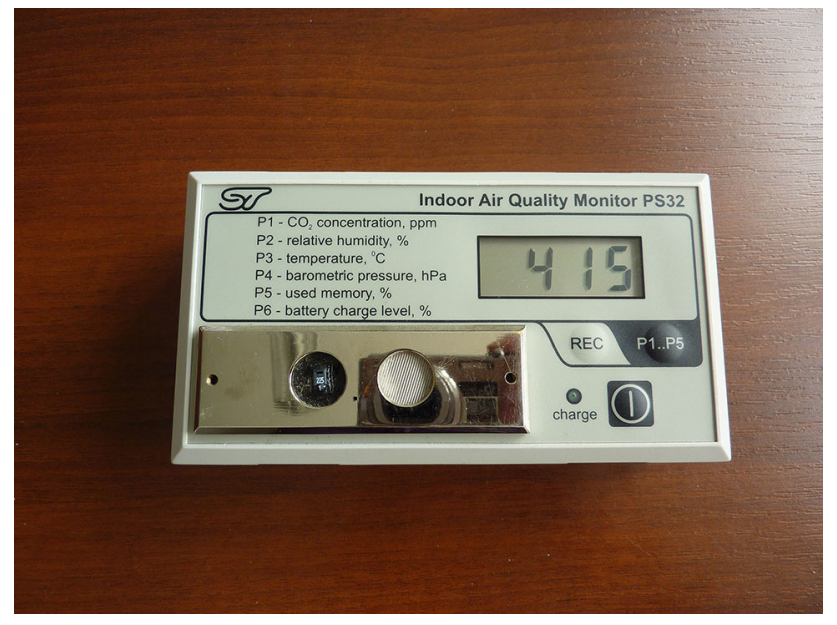

Fig. 3 Indoor air quality monitor

devices are designed to measure and record the carbon dioxide concentration as well as relative humidity, air temperature and barometric pressure.

The $\mathrm{CO}_{2}$ concentration was measured using a doublebeam detector which uses a dependence of attenuation a

Table 1 Measuring ranges and accuracy indoor air quality monitor display

\begin{tabular}{llcl}
\hline Parameter & Measuring ranges & Accuracy & Unit \\
\hline $\mathrm{CO}_{2}$ concentration & $0 \div 5000$ & 1 & $\mathrm{ppm}$ \\
Relative humidity & $0 \div 100$ & 0,1 & $\%$ \\
Air temperature & $10 \div 45$ & 0,1 & ${ }^{\circ} \mathrm{C}$ \\
Barometric pressure & $900 \div 1100$ & 1 & $\mathrm{hPa}$ \\
\hline
\end{tabular}

specific band of infrared radiation from the carbon dioxide concentration. Temperature and relative humidity were measured miniature semiconductor sensor (Table 1).

\section{Results and discussion}

\section{Statistical methods}

During the experimental period, the fan was switched on eleven times, and for case, the set of two data was selected: the carbon dioxide concentration before and one day (because of stabilization of air parameters in flats) after switching on the ventilation.

The $\mathrm{CO}_{2}$ concentration value before the action taken was estimated as the average of five consecutive measurement data (during one period between 10:00 p.m. and 12:00 a.m. at a frequency of $30 \mathrm{~min}$ ) on the day when the individual air supply system fan was turned on. The analyzed gas concentration after starting the fan in the central air handler was calculated as the average of the five consecutive measurement data (from the period 10:00-12:00) on the day immediately following the action taken.

The results of statistical analysis are shown in the example of three flats. The 'A' flat was inhabited by a twoperson family (adults), the apartment ' $\mathrm{B}$ ' by one person (adult) and the apartment ' $\mathrm{C}$ ' by a family of four ( 2 adults and 2 children). The volume and the area of flats were similar, but locations of flat ' $A$ ' was the second floor and of flat ' $\mathrm{B}$ ' and ' $\mathrm{C}$ ' was the fourth floor. Table 2 presents the carbon dioxide concentration measurement results before 
Table $2 \mathrm{CO}_{2}$ concentration measurement results before and after switching the individual air supply system fan on

\begin{tabular}{|c|c|c|c|}
\hline Flat & $\begin{array}{l}\mathrm{CO}_{2} \text { concentration } \\
\text { before }(\mathrm{ppm})\end{array}$ & $\begin{array}{l}\mathrm{CO}_{2} \text { concentration } \\
\text { after }(\mathrm{ppm})\end{array}$ & $\begin{array}{l}\text { Device operating } \\
\text { effect (ppm) }\end{array}$ \\
\hline A & 943 & 487 & 456 \\
\hline A & 592 & 490 & 102 \\
\hline A & 1069 & 514 & 555 \\
\hline A & 550 & 456 & 94 \\
\hline A & 863 & 630 & 233 \\
\hline A & 1092 & 460 & 632 \\
\hline A & 914 & 645 & 269 \\
\hline A & 1659 & 545 & 1114 \\
\hline A & 486 & 530 & -44 \\
\hline A & 575 & 492 & 83 \\
\hline A & 604 & 612 & -8 \\
\hline A & 503 & 478 & 25 \\
\hline B & 942 & 405 & 537 \\
\hline B & 894 & 871 & 23 \\
\hline B & 732 & 690 & 42 \\
\hline B & 557 & 374 & 183 \\
\hline B & 1417 & 824 & 593 \\
\hline B & 1395 & 791 & 604 \\
\hline B & 432 & 357 & 75 \\
\hline B & 1321 & 337 & 984 \\
\hline B & 612 & 352 & 260 \\
\hline B & 331 & 437 & -106 \\
\hline B & 523 & 535 & -12 \\
\hline C & 1580 & 1147 & 433 \\
\hline C & 1947 & 353 & 1594 \\
\hline C & 1848 & 1006 & 842 \\
\hline C & 2168 & 1449 & 719 \\
\hline $\mathrm{C}$ & 1256 & 1270 & -14 \\
\hline $\mathrm{C}$ & 1422 & 385 & 1037 \\
\hline $\mathrm{C}$ & 2429 & 2196 & 233 \\
\hline $\mathrm{C}$ & 1749 & 610 & 1139 \\
\hline $\mathrm{C}$ & 3050 & 2257 & 793 \\
\hline $\mathrm{C}$ & 1936 & 466 & 1470 \\
\hline C & 499 & 377 & 122 \\
\hline
\end{tabular}

and after switching the individual air supply system fan on. The difference in concentration highlights the fan effect. When measuring, the external conditions were changing (temperature, wind speed and direction) and the internal conditions significantly differed. This was because the studies were carried out in real conditions, where the person in charge has no influence on the weather conditions and the residents operation.

Measurements in flats $\mathrm{A}, \mathrm{B}$ and $\mathrm{C}$ were carried out in parallel at the same time. To make results credible, the data which had been recorded with similar parameters of external air were selected (the same before and after turn on the fan). Because the analysis includes night hours, the activities of users are the same.

The number of two tests in Table 2 is 34. These are linked due to the fact that each values pair is the analyzed parameter measurement results in the one-day interval (it is in the next night). The measurement was carried out at the same time in the same place in the apartment. The introduced action was to turn the individual air supply system fan on. The evaluated result was the difference in $\mathrm{CO}_{2}$ concentration before and after the action taken, i.e., the analyzed parameter reduction caused by turning on the fan. Negative values indicate an increase in $\mathrm{CO}_{2}$ concentration, 
which result from the fact that research is in the real conditions, i.e., in terms of several factors not under the control. The conducted univariate variance analysis revealed a significant difference in the average result with using the fan in one of the apartments (apartment A) to the other two. Based on the data, the frame graphs were created (Fig. 4) for the presented in table three apartments. Each graph shows the value of the smallest and the largest effect (difference in concentrations), median and upper and lower quartile.

The statistical inference was to verify the hypothesis about the impact lack of the action taken to reduce the average carbon dioxide concentration value. Formulated null hypothesis predicated that the expected effect value is 0 and the alternative hypothesis stated the positive value of this parameter.

The applied hypothesis test was the t-Student statistic. The test statistic value was obtained $t=5.64$, where $p<0.0001$. On this result basis, the null hypothesis was rejected in favor of the alternative hypothesis. Therefore, turning the individual air supply system fan on leads to a reduction in the average level of carbon dioxide in the room.

The implementation of the confidence range for the value of the expected effect was specified to conduct a quantitative assessment of the effects of the action taken. 95\% implementation confidence range for the considered parameter was obtained $(283.4 ; 602.9)$ (Table 3). The range contains the actual estimated parameter value. This means that only in five percent of the cases the ranges will be obtained, which will not include the expected effect of

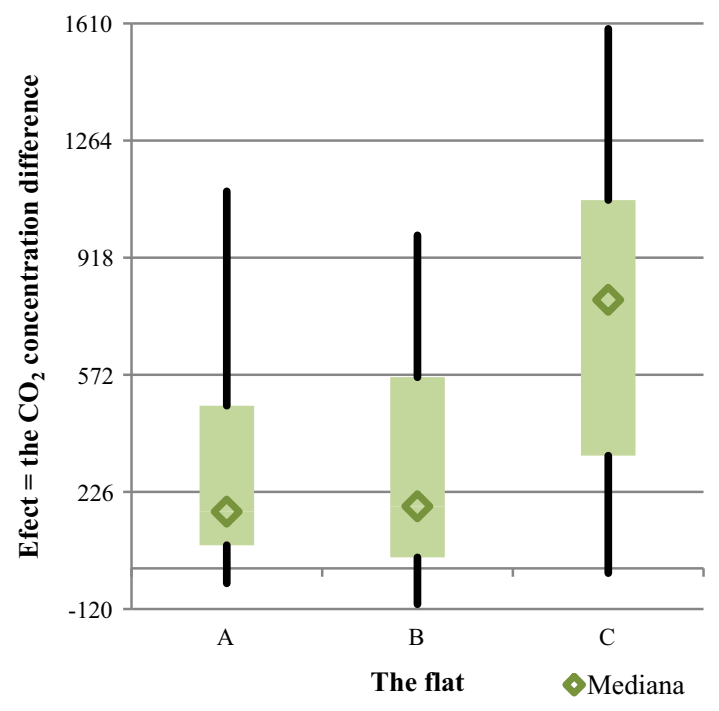

Fig. 4 Distribution of $\mathrm{CO}_{2}$ concentrations in homes covered by the study illustrated with frame graphs (in the lower left corner of the statistics value by the $\mathrm{F}$ Snedecor and corresponding $p$ value in the univariate variance analysis) device being turned on. At the assumed confidence level, the individual air supply system fan reduces the average $\mathrm{CO}_{2}$ concentration where the reduction is at least $300 \mathrm{ppm}$ but it can also be equal about 600 ppm (Fig. 5).

On the estimated values basis of selected quartiles (especially quartile and median), one can predict how often they exceeded specified $\mathrm{CO}_{2}$ concentrations (Fig. 6).

Quartile values may also be determined on the theoretical distributions basis approximating the empirical distributions. Three applied compatibility tests do not give rise to impeach the null hypothesis that using the exponential distribution or logarithm-normal distribution can

Table 3 Statistical expected value inference results of the difference between the $\mathrm{CO}_{2}$ concentration before and after switching on the fan

\begin{tabular}{llllll}
\hline Difference & Sample diff. & SE & DF & $T$-Stat & $p$ value \\
\hline Before-after & 443.12943 & 78.5202 & 33 & 5.6435084 & $<0.0001$ \\
\hline Difference & Sample diff. & SE & DF & L. Limit & U. Limit \\
\hline Before-after & 443.12943 & 78.5202 & 33 & 283.37885 & 602.87994
\end{tabular}

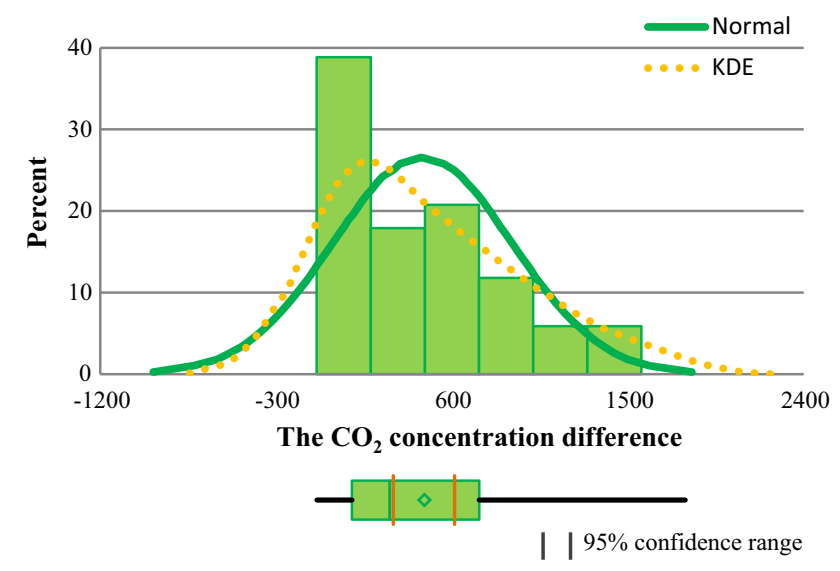

Fig. 5 Frequencies histogram for the $\mathrm{CO}_{2}$ concentration reduction after the fan is turned on and $95 \%$ confidence range for the considered characteristics expected value. KDE—-kernel density estimation-and normal distribution

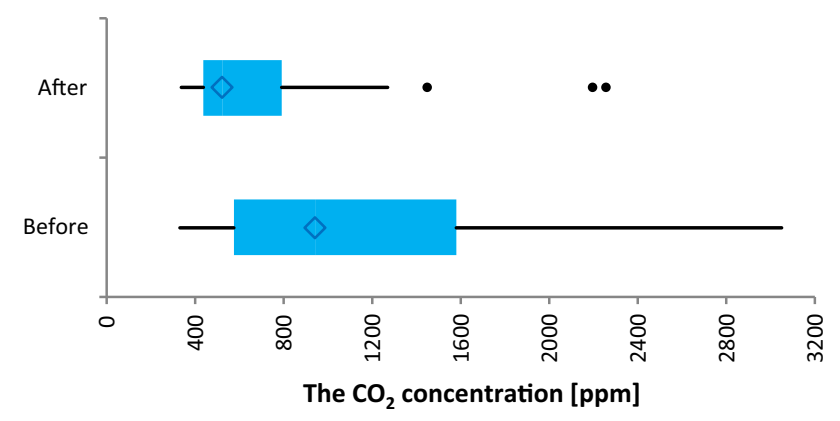

Fig. $6 \mathrm{CO}_{2}$ concentrations distribution illustrated with frame graphs, respectively, before and after the fan on 


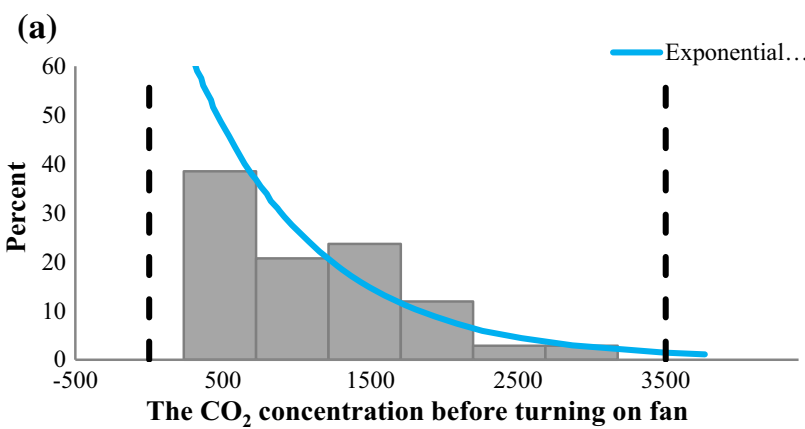

(b)

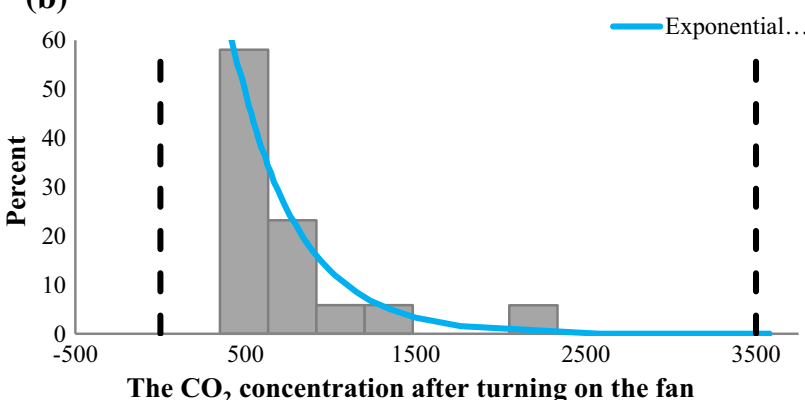

Fig. 7 Histogram and density curve of exponential distribution for $\mathrm{CO}_{2}$ concentrations. a Before turning on the fan; $\mathbf{b}$ after turning on the fan
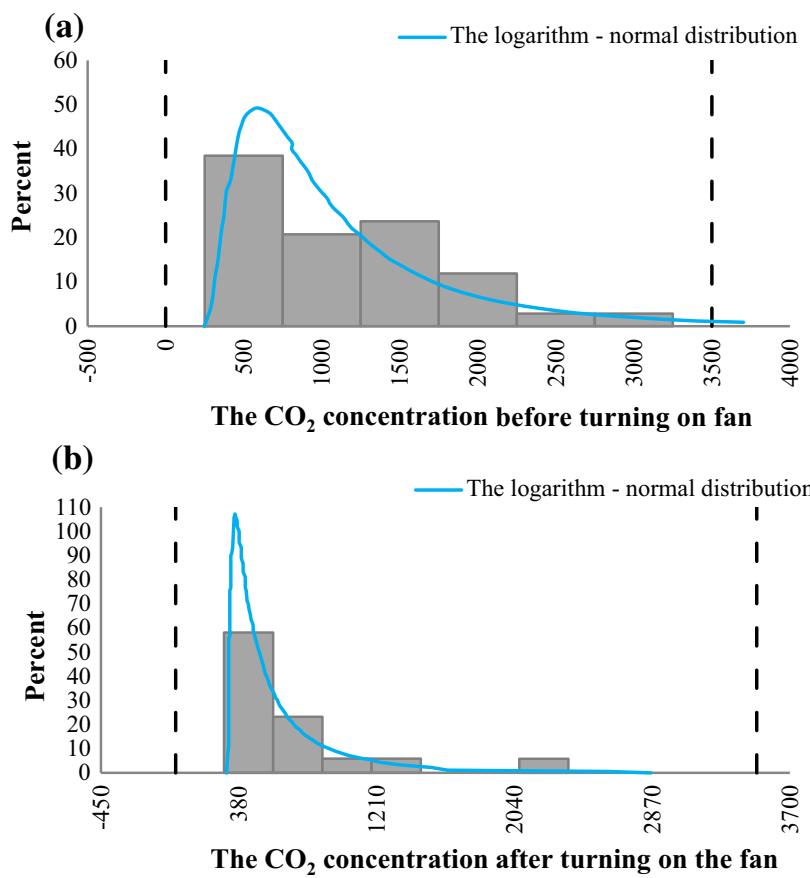

Fig. 8 Histogram and density curve of the logarithm-normal $\mathrm{CO}_{2}$ concentrations distribution. a Before turning on the fan; $\mathbf{b}$ after turning on the fan

adequately characterize the carbon dioxide concentration distribution in both conditions with individual air supply system fan on and off (Figs. 7, 8).
The research shows that the level similar to $2000 \mathrm{ppm}$ is exceeded in about $10 \%$ of the $\mathrm{CO}_{2}$ concentration measurements before turning on the fan (Table 4). After turning on the fan, quantile in the range 0.9 is significantly reduced by nearly $800 \mathrm{ppm}$ (Table 4). A similar situation is observed also in the other quantiles placed in Table 3.

\section{Results}

The ventilation with the use of individual air supply system using the natural force causing the indoor air exchange proved to be insufficient. The analysis subject was to improve the air quality after switching on the air fan. The analysis results are shown in the graphs (Fig. 9).

Charts were created for the measured data average values for all units examined. The areas between the minimum and maximum were established by rejecting extreme values. The analysis showed an improvement in the indoor air quality regardless of wind direction. For most of the analyzed housing, the lines defining the carbon dioxide concentration area with individual air supply system fan on were located closer to each other, which means less fluctuation range of the analyzed parameter and thus less influence factors associated with the weather conditions variability and apartments usage.

\section{Conclusion}

The analysis of the individual air supply system work's impact on the air quality showed fluctuations in the $\mathrm{CO}_{2}$ concentration in a narrower range when the fan was working which means less random factors influence on the air exchange. Turning on the device significantly improved the building microclimate as demonstrated by conducting statistical analysis.

After the turning on the fan, the amount of inflow air was greater than inflow by infiltration. It caused the increase in average indoor air pressure. The forces that tend to put air out increased and this caused the more intense displacement the exhaust air to the gravitational ducts. In this way, the system was changed in the supply system. Application of the proposed solution has increased exchange rate of air and eliminated reverse drafts. This made the analyzed system less dependent on wind.

The use of one air handler for all flats changed the natural ventilation system in hybrid ventilation system. In this way, whole installation can work as the gravitational system with air inflow by duct of the individual air supply system and leaks or as the mechanical supply system.

In the article, the system with turned on fan and turned off fan in continuous periods was analyzed. The next step should be change the system to the automatically 
Table 4 Carbon dioxide concentration values by measurements and estimates of the exponential and logarithmic distribution

\begin{tabular}{|c|c|c|c|c|c|c|}
\hline & \multicolumn{2}{|c|}{$\begin{array}{l}\text { Observed concentration } \mathrm{CO}_{2} \\
\text { value }(\mathrm{ppm})\end{array}$} & \multicolumn{2}{|c|}{$\begin{array}{l}\text { Estimated exponential } \mathrm{CO}_{2} \text { distribution } \\
\text { value }(\mathrm{ppm})\end{array}$} & \multicolumn{2}{|c|}{$\begin{array}{l}\text { Estimated logarithm-normal } \mathrm{CO}_{2} \\
\text { distribution value (ppm) }\end{array}$} \\
\hline & Before & After & Before & After & Before & After \\
\hline Quantile range 0.1 & 499 & 357 & 395 & 366 & 477 & 366 \\
\hline$Q 1$ & 575 & 437 & 547 & 434 & 633 & 410 \\
\hline$M$ & 942 & 522 & 887 & 586 & 922 & 519 \\
\hline$Q 3$ & 1580 & 791 & 1467 & 846 & 1417 & 772 \\
\hline Quantile range 0.9 & 1947 & 1270 & 2235 & 1189 & 2158 & 1273 \\
\hline
\end{tabular}

(a)

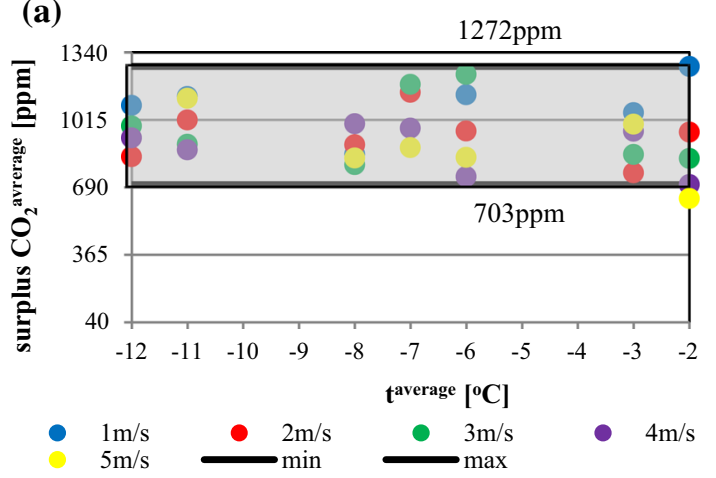

(b)

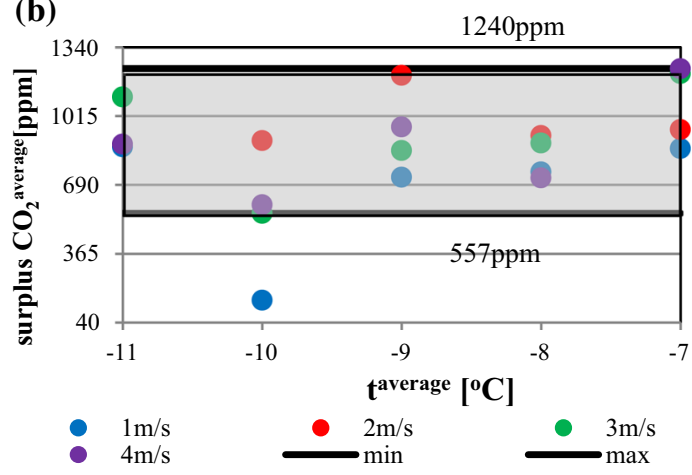

(c)

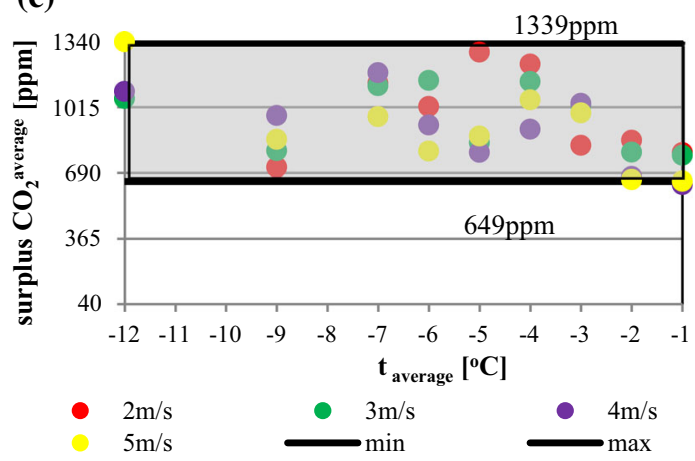

Fig. 9 Carbon dioxide average concentration range according to the average outdoor temperature taking into account the wind speed. Charts on the left-hand side-individual air supply system without (d)

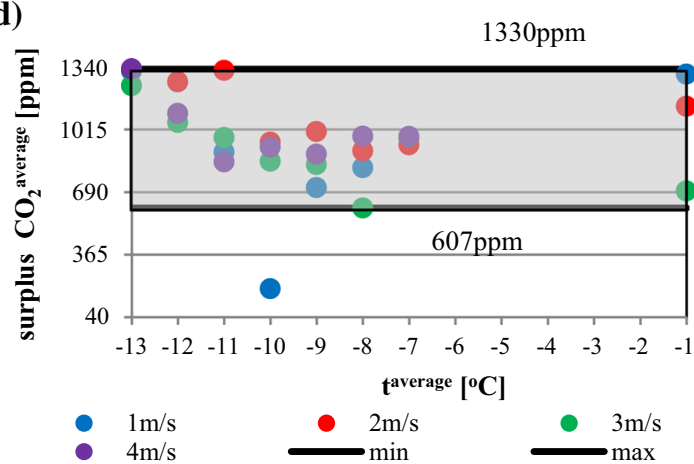

(e)
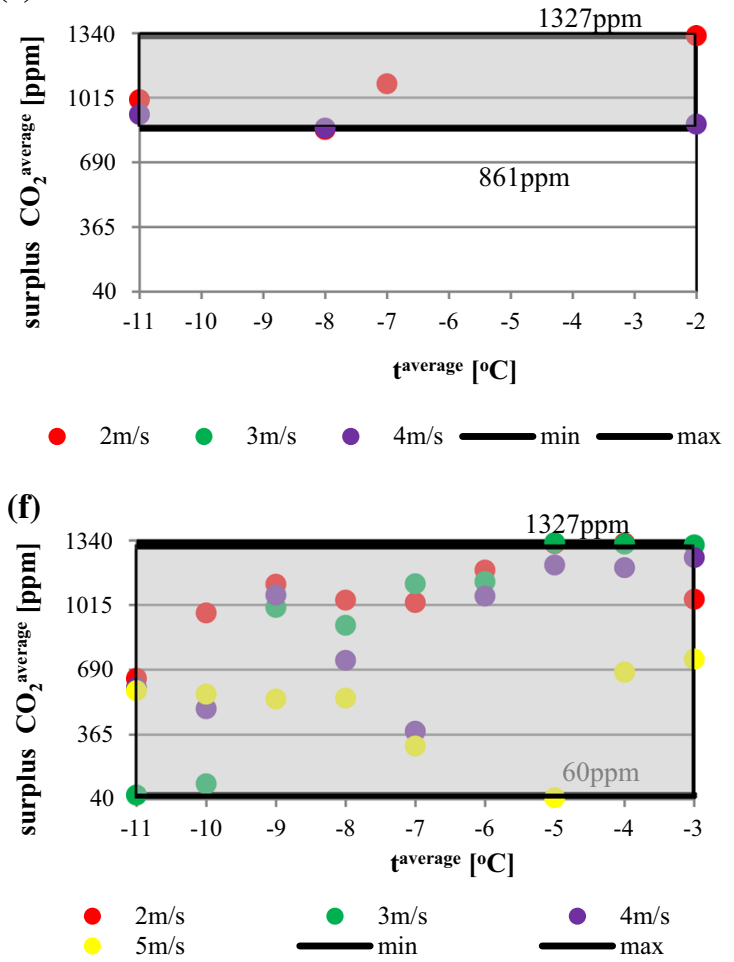

using a fan; on the right-individual air supply system with fan on. $\mathbf{a}$ and $\mathbf{b}$ wind direction to the North; $\mathbf{c}$ and $\mathbf{d}$ wind direction to the East; $\mathbf{e}$ and $\mathbf{f}$ wind direction to the West 
controlled hybrid system. In this case, the concentration of the carbon dioxide in the indoor air will be the signal to turning on or turning off the fan.

Even the use of the system without turning on the fan causes the greater air inflow, than infiltration. It is due to the high building's tightness and the high windows' and doors' airflow resistance. In addition, the supply air has a higher temperature than the outside air due to the preheating during the flow through the ducts placed in the underground garage and the vertical gravitational shafts.

The main advantage of the proposed system that distinguishes it from the typical supply ventilation is that there is no need for leading the additional ducts in the flats. The lower gravitational ducts sections which are not normally used are sufficient.

Acknowledgements This work was supported by the European Regional Development Fund under the Innovative Economy Operational Programme. Project title: 'Innovative measures and effective methods to improve the safety and durability of buildings and transport infrastructure in the sustainable development strategy' under Grant Number PO IG.01.01.02-10-106/09-00.

Open Access This article is distributed under the terms of the Creative Commons Attribution 4.0 International License (http:// creativecommons.org/licenses/by/4.0/), which permits unrestricted use, distribution, and reproduction in any medium, provided you give appropriate credit to the original author(s) and the source, provide a link to the Creative Commons license, and indicate if changes were made.

\section{References}

Ben David T, Waring MS (2017) Impact of natural versus mechanical ventilation on simulated indoor air quality and energy consumption in office in fourteen U.S. cities. Build Environ 104:320-336

Chang H, Kato S, Chikamoto T (2004) Effects of outdoor air conditions on hybrid air conditioning based on the task/ambient strategy with natural and mechanical ventilation in office buildings. Build Environ 39:153-164
McQuiston F, Parker J, Spitler J (2005) Heating ventilating, and air conditioning. Analysis and design. Wiley, New York

Nantka MB (2008) Indoor climate and energy consumption in buildings with natural ventilation. Archit Civ Eng Environ 1(3):107-118

Niachau K, Hassid S, Santamouris M, Livada I (2008) Experimental investigation of performance natural, mechanical and hybrid ventilation in urban environment. Build Environ 43:1373-1382

Nielsen TR, Drivsholm C (2010) Energy efficient demand controlled ventilation in single family houses. Energy Build 42:1995-1998

Nomura M, Hiyama K (2017) A review: natural ventilation performance of office buildings in Japan. Renew Sustain Energy Rev 74:746-754

Omrami S, Garcia-Hansen V, Capra B, Drogemuller R (2017) Natural ventilation in multi-storey buildings: design process and review of evaluation to ols. Build Environ 116:182-194

Piotrowski J, Zender-Świercz E (2008) Results of applying the individual air supply system in rooms with bifunctional boilers (in polish). Instal 12:29-30

Piotrowski J, Zender-Świercz E, Telejko M (2008) Research into indoor microclimate in flats with individual systems of air intake in view of energy saving in buildings. In: Paper presented at the SolPol - international conference, renewable energy innovative technologies and new ideas, Warsaw

Piotrowski J, Telejko M, Zender-Świercz E (2010) The impact of tight building coating for the distribution of air ventilation (in polish). Energy Build (in polish) 7:23-25

Piotrowski J, Story A, Olenets M (2015) Mathematical model of the thermal-air regime of a ventilated attic. J Civ Eng Manag 21(6):710-719

The American Society of Heating, Refrigerating and Air-Conditioning Engineers (2016) Ventilation for acceptable indoor air quality (ANSI/ASHRAE Standard 62.1 - 2016)

Zender-Świercz E, Piotrowski J (2008) Microclimate in rooms with the individual system of air intake. In: Paper presented at the 11th International conference on indoor air quality and climate, Copenhagen, Denmark

Zender-Świercz E, Piotrowski J (2009) Elimination of the negative influence of tight building. Struct Environ 1:43-46

Zender-Świercz E, Piotrowski J (2010) Development of the microclimate in rooms equipped with individual air supply system (in polish). Build Phys Theory Pract (in polish) 5(1):67-69

Zender-Świercz E, Piotrowski J (2011) Improving the inside microclimate of the multi-family buildings (in polish). Build Phys Theory Pract (in polish) 6(4):85-89 